\title{
China's wind power development
}

\author{
Daohan Tang \\ College of Humanities, Arts and Social Sciences, Flinders University, GPO Box 2100, Adelaide 5001, South Australia, Australia
}

\begin{abstract}
This paper reviews the development of wind power in China. As one of the biggest energyconsuming and the worst environment deterioration countries, Chinese government has been actively exploring wind power instead of traditional energy. In the paper, there are some unique locations selected based on favourable geographical conditions and exploring potential. Moreover, relevant wind power development policies have been clarified. On the basis of current wind power implementation, some key problems in the policies have been pointed out.
\end{abstract}

\section{Introduction}

The issues of climate change and energy depletion have been controversial concerns. National governments and international organisations have started to explore and research alternative scheme to response to a series of environmental problems and energy crisis. China, as the largest carbon emitter, it has the responsibilities for the contributions to energy saving and emission reduction. As a result, Chinese government has actively developed wind power over two decades to respond to global warming caused by large amounts of greenhouse gas (GHG) emissions.

According to Sherman et al. [1], the installed capacity of wind power has maintained a twofold increase since 2007, and by the end of March 2015, cumulative installed capacity of wind power has reached 10,107 million kilowatts, which was ahead of schedule to complete the development of wind power "Twelfth Five-Year Plan". Although the development of wind power has achieved remarkable progress, as the emerging energy industry, there are many obstacles to be solved, such as the location selection for wind farm and the policies related to energy development.

The objective of this study is going to research on the most suitable locations for developing wind power in China, and reveal the weaknesses in domestic wind power development.

\section{China's Wind Power Development and Ideal Wind Farms}

In China, the industry of wind power has developed rapidly since 20 years ago. Before that, in 1988, the Danish helped Chinese government build the first onshore wind turbine in Xinjiang, located in the northwest of the country [2]. However, due to backward concepts and a lack of foresight, the development of wind power was not taken seriously until the new millennium.
China's Meteorological Administration stated that due to the unique geographical advantages, China has huge abundant wind resources for wind power development. To be specific, the most suitable locations mainly distribute in "Three North" regions and southeast coast. According to the prediction of Energy Foundation [3], by the end of 2020 , the national total installed capacity of wind power will likely reach 25,000 to 30,000 million kilowatts, and "Three North" regions can contribute to $80 \%$ at least. "Three North" regions (Northwest, North China, and Northeast) include Northeast Provinces (Liaoning, Jilin and Heilongjiang), Inner Mongolia, Ningxia, Qinghai, Hebei, Gansu, and Xinjiang. The density of wind power generation energy range from 220 to 320 watts per square metre yearly [4]. Southeast coastal line and relevant islands that are offshore within ten kilometres of coastline Southeast coast from north to south has abundant offshore wind power resources. The Southeast coast is composed of Shandong, Jiangsu, Shanghai, Zhejiang, Fujian, Guangdong, and Guangxi. The density of wind power generation energy can reach 200 watt watts per square metre yearly [5].

Table 1. The third wind energy resource census in "Three North" regions and southeast coast

\begin{tabular}{|c|c|c|c|c|}
\hline Region & Area $\left(\mathrm{km}^{2}\right)$ & $\begin{array}{l}\text { Theoreti- } \\
\text { cal } \\
\text { reserves } \\
\text { (Ten } \\
\text { thousand } \\
\text { kilowatt) }\end{array}$ & $\begin{array}{l}\text { technical } \\
\text { exploitati-on } \\
\text { amount } \\
\text { (Ten } \\
\text { thousand } \\
\text { kilowatt) }\end{array}$ & $\begin{array}{l}\text { Potential } \\
\text { technical } \\
\text { exploitati- } \\
\text { on amount } \\
\text { (Ten } \\
\text { thousand } \\
\text { kilowatt) }\end{array}$ \\
\hline North China & 113030 & 103025 & 15912 & 1746 \\
\hline Beijing & & 498 & & 1 \\
\hline Tianjin & & 498 & & 3 \\
\hline Hebei & 7378 & 7400 & 869 & 52 \\
\hline Shanxi & 369 & 4813 & 43 & 3 \\
\hline $\begin{array}{c}\text { Inner } \\
\text { Mongolia }\end{array}$ & 105283 & 89816 & 15000 & 1687 \\
\hline
\end{tabular}




\begin{tabular}{ccccc}
\hline Northeast & 2611 & 39918 & 321 & 175 \\
Liaoning & 2100 & 8921 & 252 & 57 \\
Jilin & 511 & 9310 & 60 & 2 \\
Heilongjiang & & 21687 & & 116 \\
\hline & & & & \\
\hline Northwest & 82640 & 148685 & 12350 & 2768 \\
Shanxi & & 3808 & & \\
Gansu & 2072 & 13962 & 279 & 115 \\
Qinghai & & 40202 & & 886 \\
Ningxia & 510 & 2092 & 65 & 5 \\
Xinjiang & 80058 & 88621 & 12006 & 1762 \\
\hline & & & & \\
\hline East China & 5516 & 21074 & 829 & 88 \\
Shanghai & 342 & 310 & 49 & 3 \\
Jiangsu & 1505 & 3469 & 177 & 7 \\
Zhejiang & 850 & 2120 & 134 & 9 \\
Anhui & & 3179 & & \\
Fujian & 1809 & 2392 & 328 & 32 \\
Jiangxi & 391 & 3454 & 46 & 33 \\
Shandong & 619 & 6150 & 95 & 4 \\
\hline
\end{tabular}

Table 1 further illustrates that the top four regions have tremendous development prospects of wind power, which are the key development areas and have priority to access to resources for developing [2]. Based on Theoretical reserves, Northwest regions have the richest resources, which equals to 1.48685 billion kilowatt, followed by North China, Northeast regions and East China that equal to 1.03025 billion kilowatt, 399.18 million kilowatt and 210.74 million kilowatt respectively, accounting for $34.4 \%, 23.8 \%, 18.7 \%$ and $9.4 \%$ of the total reserves of wind energy resources in China. Based on technical exploitation amount, the largest amount of development is in North China, followed by the northwest, east and northeast regions, respectively, 159.12 million kilowatt, 123.50 million kilowatt, 8.29 million kilowatt and 3.12 million kilowatt respectively, which occupies $0.5 \%$, $41.6 \%, 2.8 \%$ and $1.0 \%$ of the technical exploitation amount in China. According to the potential technical exploitation amounts in Northwest regions and North China are estimated as 27.68 million kilowatt and 17.46 million kilowatt respectively, which account for $35 \%$ and $22.1 \%$.

According to He [2], technical exploitation amount is a key indicator in the development of wind power. Technical exploitation amount can be defined as the largest output that can be achieved based on current technology. In other words, with the development of science and technology, the exploitation amount can be explored and increased [3]. For example, it is estimated that Xinjiang has vast deposits of wind resources, which is able to reach 886.21 million kilowatt. However, under the current conditions of technology, the amount of wind resources can be utilized only 150 million kilowatt, which means that the actual installed capacity is much smaller than the technical exploitation amount. From the table 1, it can be observed that the gaps between theoretical reserves and technical exploitation amount among the listed regions are still wide.

\section{China's Wind Power Development Policy}

As the pioneers in wind energy utilization, most of advanced nations like Denmark, the United States etc. have accumulated rich and valuable development experience in wind power [6]. These countries do not only enjoy favourable geographical conditions, but also possess gradual improved and complex policies to support their wind power development. As an up-rising star, China has already made great achievements in developing wind power. Chinese government has gradually established a complete system encouraging the development of wind power.

At the national level, as mentioned above, the first onshore wind farm was built in Xinjiang in 1980's. However, the development of wind power was not given sufficient attention until 2000's [2]. Because there were two reasons that resulted in low speed development in wind power [7]. Firstly, people did not realise the importance of environmental awareness, which led to pollution issues related to excessive energy consumption. Secondly, unsound polices damaged related stakeholders' interests. For example, before 2000, under the premise of being contrary to market discipline, the government required power supply plants to buy the electricity generated by wind power with a higher price in order to shift the costs and encourage wind power development. However, due to lacks of legal constraints, some of power supply plants refused to spend money on that, and led to disorderly development in wind power industry [8].

The situation has been changed since 2003 due to the breakup of monopoly. The State Power Corporation was split in several companies by the State Council [8]. The central government also introduced competition mechanism to stimulate industry development. Meanwhile, a new generation of leader groups decided to promote and develop clean energy to face global environmental issues. The NDRC took the responsibilities for energy reform matters [7].

A tax reform policy regarding developing wind power was acted in 2004, which aimed to build a mechanism basing on protecting the benefits of grid operators while safeguarding the interests of wind power operators. A preferential system got involved in the mechanism to encourage the reduction of the related levy when large wind power projects were implemented [9].

In the mechanism, the NDRC introduced bidding to choose the most suitable provider [8]. After official announcement regarding investment plans is released, investors offer their quoted price, and the government selects the lowest offer as a supplier. In addition to the quoted price, it is expected that the amount of equipment to be produced domestically would be declared in all bids. As an additional condition, the ratio of wind power equipment localization must reach an index set up by the government, which aims to encourage and stimulate domestic wind power development [9].

As one of the biggest energy-consuming nations, China shoulders more responsibilities for solving environmental issues and energy depletion. Therefore, Renewable Energy Law was formulated and acted in 2005. In this law, development status of clean energy was reaffirmed. To be specific, there are two key points mentioned in the law. Firstly, confirming of $15 \%$ of the 
energy consumption must come from clean energy by 2020. Secondly, power companies have an obligation to ensure that wind power must occupy $5 \%$ of the master energy output in the same period. Therefore, the relationship of supply and demand is protected by the law, which results in soaring growth in the following years.

China's wind power exploitation has experienced rapidly development. At present, the scale of wind power development, the level of technical equipment, and the supportive policies of renewable energies have achieved great progress. The ability to run large-scale wind power grid electricity has also entered the ranks of the world's leading. However, some of problems and challenges have been merged [11].

High cost impedes wind power development. Specifically, the costs of wind power generally include capitalized cost and operating cost. The former cost incorporates wind turbine purchase, foundation installation and construction; the latter cost mainly focuses on maintaining safe and normal operation of the units [7].

Meanwhile, compared to thermal power, the cost of wind power is higher. Without the consideration of environment, the cost of thermal power was AU\$ 0.05$0.08 / \mathrm{kWh}$. But wind power is AU\$ 0.04 higher than thermal power. Nevertheless, if the environmental factors can be taken into account, the costs of two types of powers can be even. In the meantime, the Chinese government now are vigorous supporting the development of clean energy and provides many preferential policies, such as subsidies and tax reduction. However, how to change the position from passive support to active profitability need to be considered by wind power operators.

For the Chinese government, the technical bottlenecks have been solved, but now how to improve the policies to promote market is a new challenge. Renewable Energy Law and other relevant regulations promote the rapid growth of wind power, while some problems have been exposed as well: (1) the law is imperfect and loopholes existed; (2) policies implementation is not enough; (3) many priorities for wind power development policy are difficult to implement; (4) wind turbine testing agencies and monitoring standards lack impartiality, and the system of wind power equipment technical certification is imperfect; (5) some local governors blindly develop wind power to pursue political performance for individual career; (6) The current pricing mechanism of wind power is not perfect, which would lead to investment risks. Therefore, to make wind power that can be long-term development, policies must be continuously improved to adapt to the new condition.

\section{Conclusion}

Due to environmental issues and energy depletion, renewable energy has been emphasised the Chinese government. Wind power has irreplaceable advantages in the long term development, therefore, Chinese government vigorously devotes to wind power research and implication. Although there are many challenges impeding the process of wind power development, the Chinese government has been improving relevant policies to promote market mechanisms and cultivating all positive conditions for wind power development.

\section{References}

1. P. Sherman, X. Chen and M.B. McElroy, Springer Nature, 7 (2017)

2. D.X. He, China renewable energy development strategy research series: wind energy volume (2015)

3. Energy Foundation, China 2050 High Renewable Energy Penetration Scenario and Roadmap Study (2015)

4. W.H. Zhao, K.L. Zhong, L. Mao and D. Ye, DEA and Malmquist Index, 3, 448-453 (2016)

5. X.L. Wang, X. Lu, S.Y. Liu and J.T. Lin, Acta Scientiarum Naturalium Universitatis Pekinensis, Interannual, 52, 837-47 (2016)

6. F. Hvelplund, P.A. Østergaard and N.I. Meyer, Energ. Policy, 107, 573-584 (2017)

7. Y. He, Y. Xu, Y. Pang, H. Tian and R. Wu, Renew. Energ., 89, 695-705 (2016)

8. B. Deng, China's wind power development of the status quo, problems and countermeasures research, (2006)

9. Z.F. Tan and L.W. Ju, J. North China Electric Power Uni. (Soc. Sci.), 2, 1-7 (2013)

10. B. Lin and Z. Zhang, Renew. Sust. Energ. Rev., 58, 1387-1394 (2016) 